\title{
Experimental studies on manufacturing of the complex shapes made from copper
}

\author{
Alina Ioana POPAN ${ }^{1, *}$, Bogdan $\mathrm{LUCA}^{1}$ and Alexandru CAREAN ${ }^{1}$ \\ ${ }^{1}$ Technical University of Cluj-Napoca, B-dul. Muncii, No. 103-105, 400114, Cluj-Napoca, Romania
}

\begin{abstract}
The paper presents the manufacturing process of a complex copper electrode. To process complex copper shapes is difficult because the material is soft and very sticky. The paper presents the steps for processing this copper electrode at a high dimensional accuracy and a good surface quality. For this process a special tooling solution is needed, optimal process parameters, smart $\mathrm{CAD} / \mathrm{CAM}$ software and precise $\mathrm{CNC}$ equipment.
\end{abstract}

\section{Introduction}

CNC milling technology is one of the most important methods used in industry to machine materials [1,2]. It has various distinct advantages over the other cutting technologies, such as: high machining versatility, high flexibility and has been proven to be an effective technology for processing various engineering materials [3-5].

Current trends in the manufacturing industry require parts to be processed in a short time, with a good surface quality, high dimensional accuracy and complex 3D shapes $[6,7]$. For manufacturing 3D complex parts are used a variety of CNC machines, such as: 3 or 5 axis milling machines, multitasking lathes, 6 axis robots, or even abrasive water jet centers [8-11].

To manufacture complex 3D parts is important to use CAD/CAM software. This kind of software must have various strategies for processing complex $3 \mathrm{D}$ shapes with fine details [12-14].

The electrodes which are used in electrical discharge machining are made from two materials graphite or copper. In this paper is presented the manufacturing process for a complex copper electrode. To obtain a good surface quality and a high dimensional accuracy for copper cutting are required dedicated tools for this type of application [15, $16]$.

Using wrong combination between tool geometry and process parameters, an accumulation of material against the rake face (built up edge - BUE) can appear. The built up edge can generate in this case a poor surface finish or tool brake [17].

\footnotetext{
* Corresponding author: alina.luca@tcm.utcluj.ro
} 


\section{The 3D model}

The study was started with a 3D model, as in figure 1 . This $3 \mathrm{~d}$ model represents a copper electrode, designed for processing a complex mould.

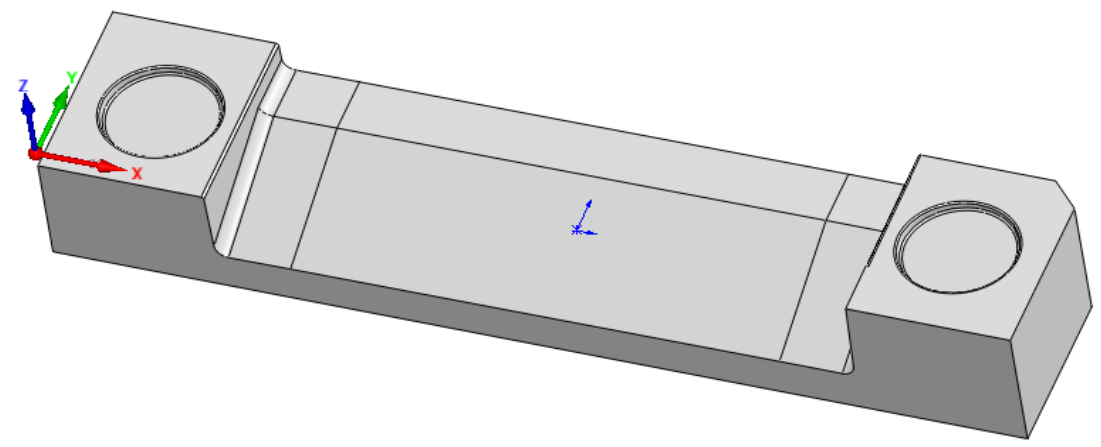

Fig. 1. The 3D model of the electrode.

\section{Tools and process parameters}

Copper alloys are difficult to machine by using normal tools, because they are very sticky. For process this copper electrode was chosen a special type of end mill made by Guhring Company.

To avoid the built up edge was selected a tool geometry with sharp edge and polished rake face. The end mills are made out of carbide, with 3 flutes and a bright surface finish with radial coolant ducts. 2.

For roughing operations an end mill with the code $3367 / 12.00$ was selected, as in figure

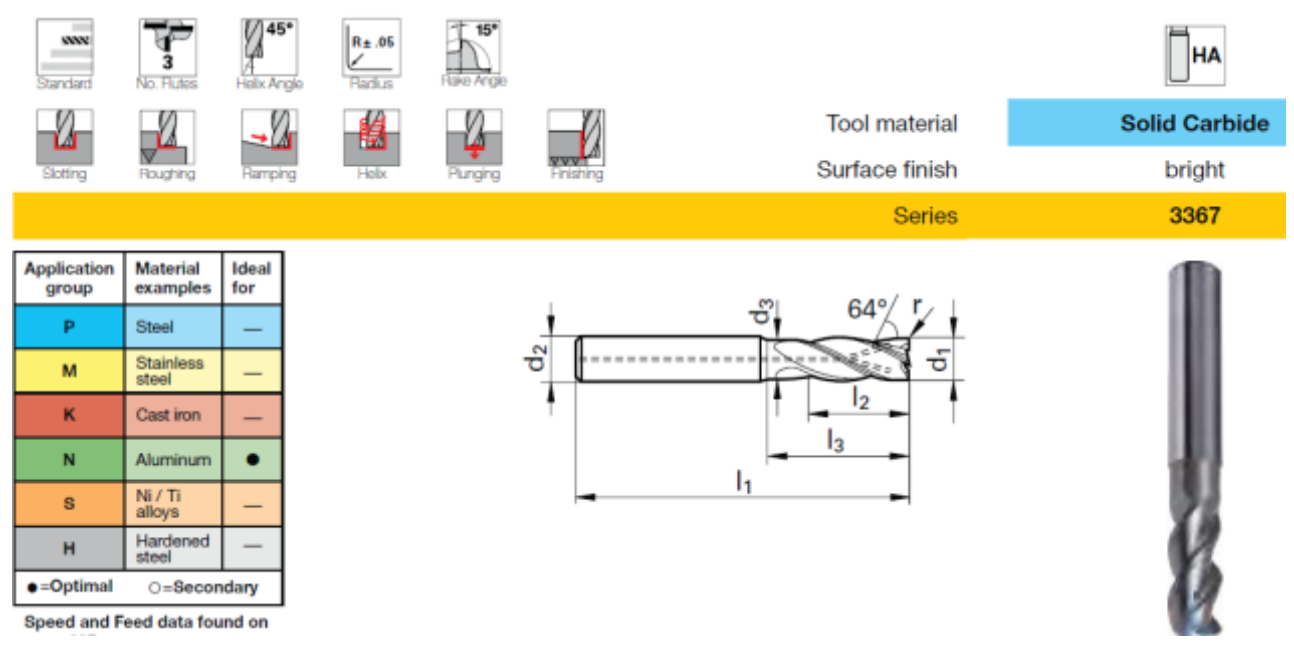

Fig. 2. The tool for the roughing operation.

The process parameters for roughing operation are:

- End mill 12 mm, code: 3367/12.000 
Rotation speed: 3342 RPM; Feed Rate: $614 \mathrm{~mm} / \mathrm{min}$; Depth of cut: $\mathrm{A}_{\mathrm{p}}=1 \mathrm{~mm}$; Width of processing: $A_{e}=12 \mathrm{~mm}$.

\begin{tabular}{|ll|}
\hline Master data $\mathbf{3 3 0 9} / \mathbf{3 . 0 0 0}$ \\
Standard: & DIN 6527L \\
Type: & W \\
Tool material: & Carbide \\
Surface finish: & Bright \\
Shank form: & DIN 6535-HA \\
\hline
\end{tabular}

Fig. 3. The second tool for the roughing operation.

- End mill 3mm, code: 3309

Rotation speed: 10800 RPM; Feed Rate: $250 \mathrm{~mm} / \mathrm{min}$; Depth of cut: $\mathrm{A}_{\mathrm{p}}=0.18 \mathrm{~mm}$; Width of processing: $A_{e}=0.05 \mathrm{~mm}$.

For finishing operations was chosen a ball mill with code 3015, as in figure 4 .

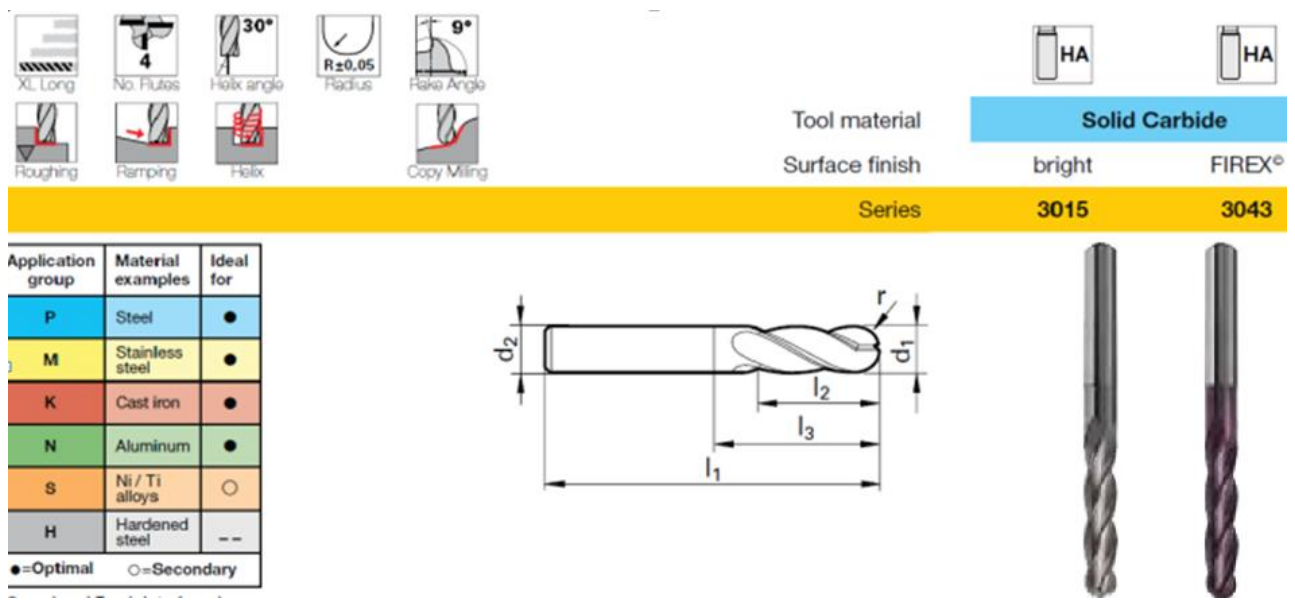

Fig. 4. The tool for the finishing operation.

The process parameters for finishing operation are: ball mill $3 \mathrm{~mm}$, code: 3015; Rotation speed: 11400 RPM; Feed Rate: $950 \mathrm{~mm} / \mathrm{min}$; Depth of cut: $A_{p}=0.18 \mathrm{~mm}$;

The processing width, $\mathrm{A}_{\mathrm{e}}$ is an important parameter for finishing of $3 \mathrm{D}$ complex surfaces. It has a direct influence on the surface quality.

To calculate this parameter the next formula can be used:

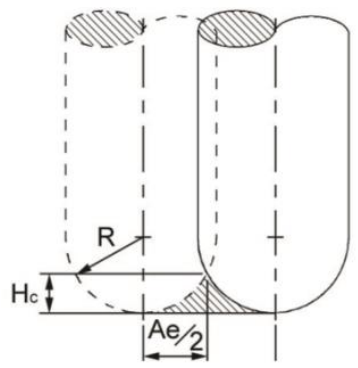

$$
\begin{aligned}
& H c=R-\sqrt{R^{2}-\left(\frac{A e}{2}\right)^{2}} \\
& A e=2 \sqrt{R^{2}-(R-H c)^{2}}
\end{aligned}
$$

Fig. 5. The width of processing, $A_{e}$. 
In this formula the $\mathrm{H}_{\mathrm{c}}$ parameter represents the height of the surface roughness.

To convert $\mathrm{H}_{\mathrm{c}} \mu \mathrm{m}$ in the general parameter for surface quality $\mathrm{R}_{\mathrm{a}} \mu \mathrm{m}$, table 1 can be used [18].

Table 1. To convert $\mathrm{Hc} \mu \mathrm{m}$ in $\mathrm{Ra} \mu \mathrm{m}$.

\begin{tabular}{|c|c|c|c|c|c|c|c|c|}
\hline$H_{C}(\mu \mathrm{m})$ & 0,2 & 0,4 & 0,7 & 1,25 & 2,2 & 4 & 8 & 12,5 \\
\hline$R_{A}(\mu \mathrm{m})$ & 0,03 & 0,05 & 0,1 & 0,2 & 0,4 & 0,8 & 1,6 & 3,2 \\
\hline
\end{tabular}

In our study the width of processing was calculated at $A_{e}=0.05 \mathrm{~mm}$.

\section{Experimental studies}

For manufacturing the electrode was used a CAD/CAM software solution (SolidWorks and SolidCAM). The first step was roughing operation. For this was chosen the application High Speed Machining and Contour Roughing strategy. For finishing operation was selected the Constant $Z$ strategy, in case of complex surfaces and Linear strategy processing for flat surfaces. The process simulation is presented in figure 6.
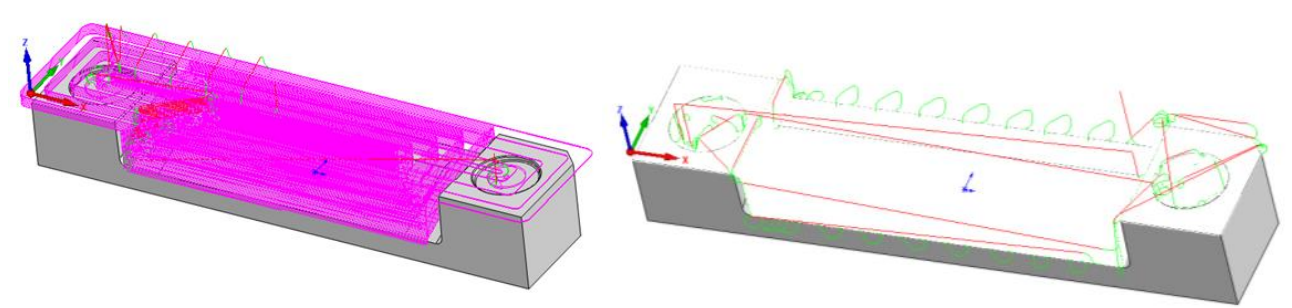

Fig. 6. The process simulation.

For this experimental study a 3 axis CNC Milling Centre was selected, HAAS VF2, with HAAS controller, from the Tehnical University of Cluj-Napoca. To fix the workpiece a special clamping device was developed, presented in figure 7.

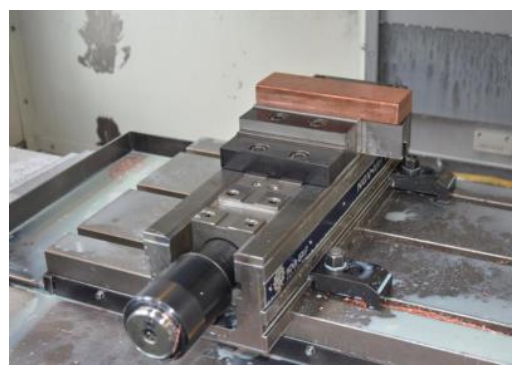

a.

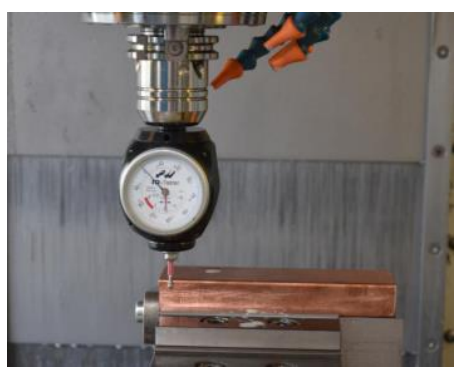

b.

Fig. 7. a. The clamping system b. Defining the work offset.

Using a 3D Probing Device, the work offset of the part was taken and the required tools were measured (see figure 7). 


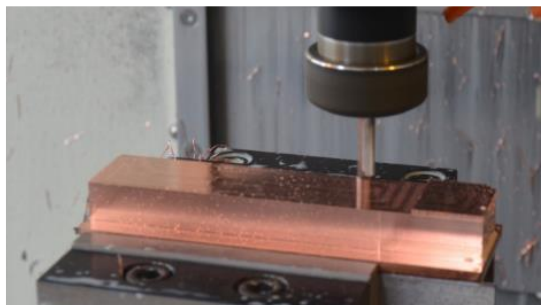

a.

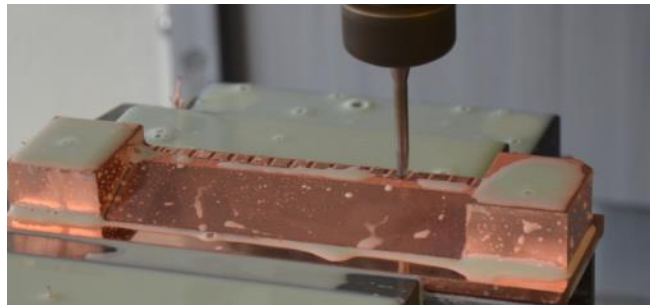

b.

Fig. 8. a. Roughing operation, b. Finishing operation.

For clamping the tools was used a tool holder with ER32 collet chuck. The cutting process was using internal and external cooling with fluid (for $12 \mathrm{~mm}$ end mill). In figure 9 are presented different phases of the machining process.
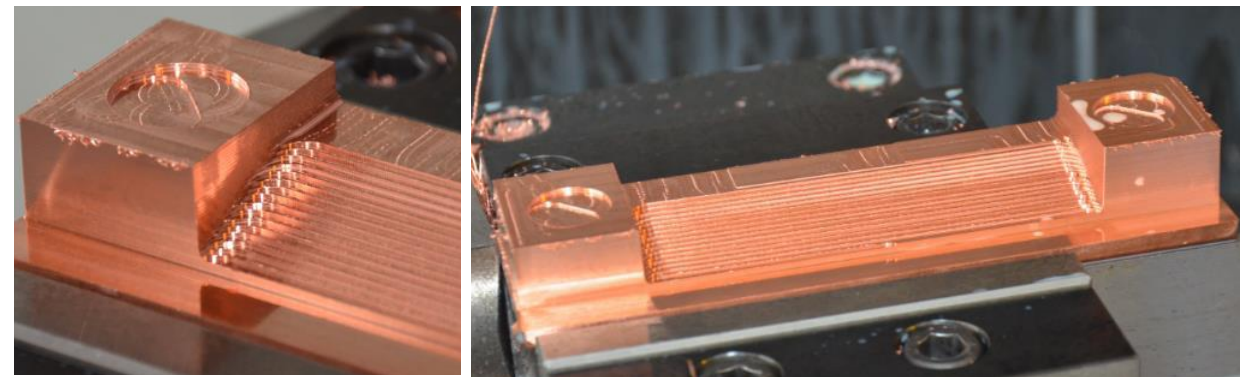

Fig. 9. Roughing operation with $12 \mathrm{~mm}$ end mill.

The entire roughing operation lasted 0.5 hour. The finishing phase of the process lasted 6.3 hours.

\section{Investigation results}

The manufactured electrode is illustrated in figure 10. Using a surface roughness tester Mitutoyo Surftest SJ-210 was measured the surface quality $\left(R_{a} \max 0.18 \mu \mathrm{m}\right)$. The maximum dimensional accuracy, $0.03 \mathrm{~mm}$ was obtained during the measurements.
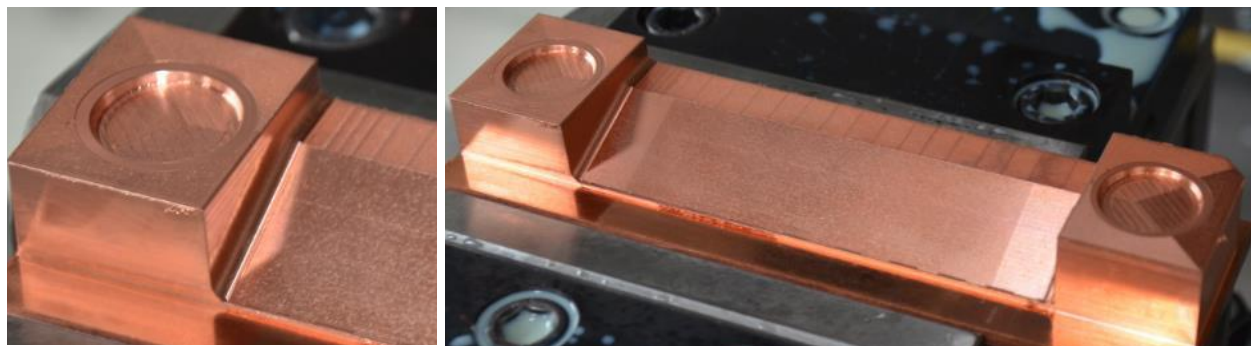

Fig. 10. The copper electrode.

\section{Conclusions}

This paper presents an experimental study for manufacturing a complex copper electrode. 
The main problem of this application is built up edge. The built up edge must be avoided to obtain good surface quality and dimensional accuracy.

To manufacture complex 3D shapes out of copper one must have:

- CAD/CAM software with smart processing strategies;

- Special tools for processing copper;

- The proper cutting parameters;

- Cutting fluid is required.

This work was supported by a grant of the Romanian National Authority for Scientific Research and Innovation, CNCS/CCCDI-UEFISCDI, project number PN-III-P2-2.1-BG-2016-0216, within PNCDI III and the H2020 AMaTUC project (GA 691787).

\section{References}

1. N. Panc, V. Bocanet, M. Bulgaru, C. Beldean, Acta Technica Napocensis, Series Applied Mathematics and Mechanics, 57(1) (2014)

2. I. A. Popan, A. I. Popan, S. C. Cosma, A. Carean, CoSME'16, doi: 10.1051/matecconf/20179402011 (2017)

3. I. Vuscan, N. Panc, Ed. Scoala Ardeleana, Cluj-Napoca, (2015)

4. M. Mera, S. Comsa, M. Damian, O. Mera, Conference of Technics and Engineering, ISBN 973-8254-07-8, 645 (2001)

5. I. A. Popan, N. Balc, A. I. Popan, D. Fratila, A. Trif, Applied Mechanics and Materials 808, 54 (2015)

6. A. Carean, I. A. Popan, M. Carean, AJME, Vol. 11, Issue 3, ISSN 1583-7904, 50 (2013)

7. A. Trif, M. Borzan, D. Fratila, V. Ceclan, , A. Popescu, Conference - Automation in Production, Planning and Manufacturing, ISBN 978-80-89276-41-7, 170 (2014)

8. R. Curta, N. Balc, A. Carean, DAAAM, 1155 (2010)

9. I. A. Popan, N. Balc, B. Luca, A. I. Popan, A., Applied Mechanics and Materials Vol 808, 339 (2015)

10. N. S. Reddy, P. V. Rao, Int. J. Adv. Manuf. Technol. 26, 1202 (2005)

11. N. Balc, AJME, Vol. X, Issue 1, ISSN 1583-7904, 12, (2012)

12. I. A. Popan, A. Carean, I. A. Popan, V. Ceclan, N. Balc, AJME, 11, 42 (2013)

13. J. Paulo Davim, V.N. Gaitonde, S.R. Karnik, Journal of materials processing technology 20516 (2008)

14. V. A. Ceclan, I. A. Popan, S. D. Grozav, C. Miron-Borzan, I. Kuric, Applied Mechanics and Materials 808, 286 (2015)

15. Guhring Tool Catalogue (2017)

16. I. A. Popan, N. Balc, B. Luca, A. I. Popan, Acta Technica Napocensis, Series Applied Mathematics and Mechanics, 66, 153 (2015)

17. A.B. Junior, A.E. Diniz, F.T. Filho, The International Journal of Advanced Manufacturing Technology, 43, 756 (2009)

18. $* * *$ www.mstar.ro (Dormer) 